\title{
강변여과용 집수정의 산출유량 예측공식 비교 Comparison of the Prediction Methods for Production Rate of Collector Well in Riverbank Filtration
}

\author{
김승현 · 곽재혁 ${ }^{\dagger}$ \\ Seung-Hyun Kim • Jae-Hyeok Kwak ${ }^{\dagger}$ \\ 영남대학교 환경공학과 \\ Department of Environmental Engineering, Yeungnam University
}

(Received April 5, 2018; Revised June 29, 2018; Accepted July 6, 2018)

\begin{abstract}
In this study, the Milojevic formula, the Hantush formula, and the numerical method, which are the three different methods used to predict the production rate of collector wells in riverbank filtration, were compared. Given a collector well placed in a hypothetical geologic formation, the production rate of the collector predicted by each method was as follows: $5,972 \mathrm{~m}^{3} / \mathrm{day}$ by the Milojevic formula, $5,286 \mathrm{~m}^{3} /$ day by the Hantush formula, and $6,600 \mathrm{~m}^{3} /$ day by the numerical method. From these results, the Hantush formula appears to make the safest prediction. However, the Milojevic formula and the Hantush formula cannot take into account the clogging of riverbed which is inevitable in riverbank filtration. Therefore, for now the best method to apply in a collector well design in riverbank filtration is the numerical method with clogging layer included.
\end{abstract}

Key Words : Riverbank Filtration, Production Rate, Hantush, Milojevic, Numerical Method

요약 : 강변여과용 집수정의 산출유량 설계에 적용되는 3가지 기법인 Milojevic식, Hantush식 그리고 수치해법을 비교하였다. 가상의 지층에 강변여과용 집수정을 설치하는 경우 이들 기법으로 예상되는 산출유량을 구했으며, 각각 $5,972 \mathrm{~m}^{3} / \mathrm{day}, 5,286$ $\mathrm{m}^{3} /$ day 그리고 $6,600 \mathrm{~m}^{3} /$ day이었다. 이로부터 Hantush공식이 가장 보수적 예측임을 알 수 있었다. Milojevic과 Hantush공식은 실제 강변여과에서 일어나는 하상폐색을 고려할 수 없는 한계를 가진다. 따라서 하상폐색을 고려한 수치해법을 적용하는 것 이 강변여과용 집수정 설계에서 최선의 방법이라 할 수 있을 것이다.

주제어 : 강변여과, 산출유량, 한투쉬, 밀로제빅, 수치해법

\section{1. 서 론}

최근 우리나라에서도 강변여과가 실용화하기 시작하면서 많은 양의 여과수를 얻기 위한 집수정(collector well)이 다수 건설되었으며, 이중에는 산출유량이나 여과수질 면에서 모두 성공적인 사례도 있으나 그렇지 못한 경우도 있다. 그런데 산출유량이 부족한 경우는 물론이고, 여과수질 면에서 성공 하지 못한 사례들도 산출유량 부족이 문제의 원인인 경우가 대부분이어서 산출유량의 안전한 확보가 강변여과의 성패를 좌우하는 매우 중요한 사항이라 할 수 있다. 강변여과수를 구성하는 두 요소는 여과하천수와 자연지하수인데, 여과하 천수의 양이 충분하지 않으면 대수층에서 용출될 수 있는 독성물질에 취약한 자연지하수의 비중이 커지기 때문이다.

집수정은 1930년대 석유시추용으로 미국인 Leo Ranney에 의해 고안된 후, 대용량의 지하수를 개발하는 용도로도 사 용되었으며, 현재는 대용량 강변여과수를 개발하는 주요한 장치로 세계적으로 널리 사용되고 있다. ${ }^{1)}$ 집수정을 이용한 강변여과의 산출유량을 예측하는 방식은 크게 몇 가지로 나 뉜다. 첫째는 Hantush ${ }^{2)}$ 공식 계열로 이들은 집수관을 '유입 율이 균등한 유한한 길이의 선형싱크(sink)'로 보고 집수정의 수위저하와 산출유량의 관계식을 얻는다. 이 방법론은 강
변여과 이외의 다양한 경계조건에도 적용된 바 있으며, 그 예로는 Zhan 등 ${ }^{3)}$, Park과 Zhan ${ }^{4)}$, Zhan과 Park ${ }^{5)}$ 등을 들 수 있다. 둘째는 경험공식들로, 그 대표적인 예는 Milojevic ${ }^{6}$ 식 을 들 수 있다. 이 공식은 강변여과를 모사하는 물탱크를 실 험장치로 이용하되 물흐름 대신 전류를 통하여 수평집수관 의 배치에 따른 여과수 산출유량을 파악하는 '전기수리학적 유사모델실험, 방식을 택했다. 셋째로는 수치해법을 적용하 는 방식이며, 다양한 현장조건을 쉽게 반영할 수 있어서 현 재 가장 널리 사용되고 있다. ${ }^{7}$

본 연구에서는 가상의 강변 대수층을 설정하고, 여기에서 집수정을 이용한 강변여과수를 개발하는 경우, 위의 각 방 식들을 적용하여 얻은 산출유량을 비교함으로써 이들의 특 성을 파악하고자 하였다. 특히, Hantush공식은 매우 복잡하 여 아직 국내의 강변여과에서 적용된 바 없으므로 이의 활용 법을 소개함으로써 앞으로 실용되는데 보탬이 되고자 하였다.

\section{2. 대수층과 집수정 설정}

본 연구에서 적용하는 가상의 강변 대수층에 대한 개요도 는 Fig. 1에 나타내었다. 대수층은 Hantush나 Milojevic이 제 


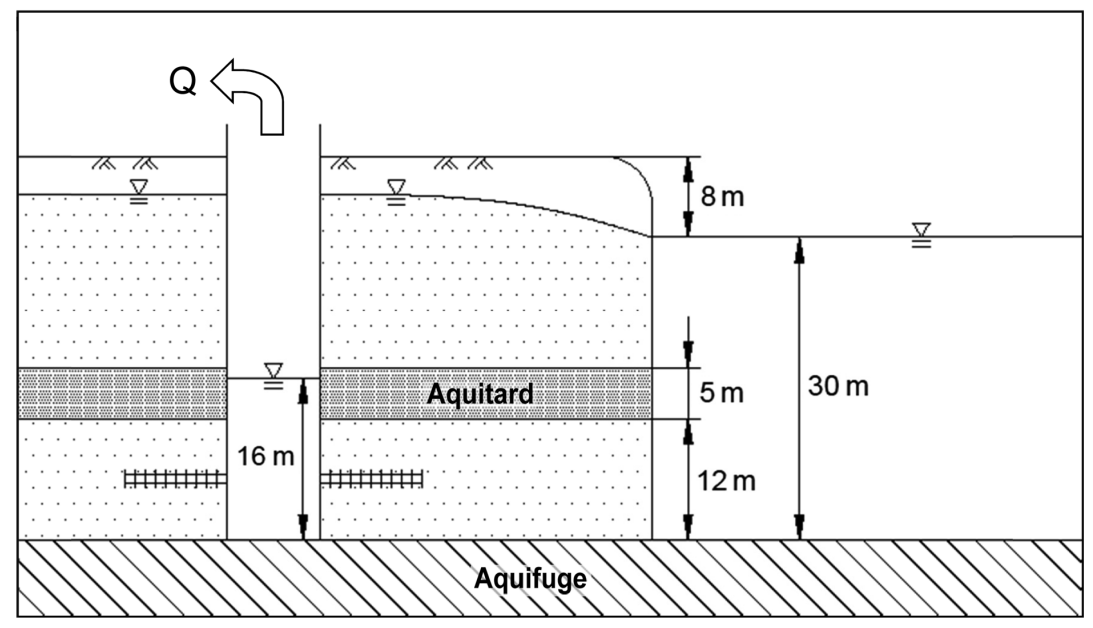

Fig. 1. Schematization of the aquifer for the model riverbank filtration.

시한대로 피압대수층이고 하상에는 퇴적층이 없는 것으로 가정하였다. 피압대수층의 두께는 $12 \mathrm{~m}$, 기반암으로부터의 하천수심은 $30 \mathrm{~m}$, 불투수층의 두께는 $5 \mathrm{~m}$ 로 가정하였으며, 우물통(caisson)의 직경은 $5 \mathrm{~m}$, 우물통의 지표하 매설깊이 는 $38 \mathrm{~m}$ 로 보았다. 기반암은 수평으로 가정하였다. 수평집수 관의 개수는 9 개, 직경은 $35 \mathrm{~cm}$, 길이는 $20 \mathrm{~m}$ 로 보았으며, 우물통의 중심은 수변선에서 $100 \mathrm{~m}$ 이격한 것으로 가정하였 다. 하천의 폭은 $400 \mathrm{~m}$ 로 보았다.

\section{3. 계산결과 및 고찰}

강변여과는 깨끗하지 않은 하천에서 깨끗한 물을 얻는 공 법이므로 하상에는 필연적으로 폐색층(clogging layer)이 형 성되며, 이 층의 두께는 수 $\mathrm{mm} \sim$ 수 $\mathrm{cm}$ 로 경우에 따라 다르 고, 그 투수계수는 대수층 투수계수의 $1 / 100 \sim 1 / 1,000,000$ 정도로 작다고 한다. ${ }^{89}$ 수치해법과 달리 Hantush공식이나 Milojevic공식은 폐색층이나 또는 투수계수가 다른 여러 지 층을 직접 고려할 수 없는 한계를 가지며, 본 연구에서는 이 러한 특성을 감안하여 강변여과에도 불구하고 하상에 폐색 층은 형성되지 않는다고 가정하였다.

\subsection{Milojevic공식에 의한 산출유량}

Milojevic ${ }^{6}$ 은 강변여과용 집수정의 산출유량공식으로 단 독집수정과 군집수정에 대한 공식을 따로 제시하였다. 군집 수정을 사용하는 경우 집수정 사이의 간섭에 의해 각 집수 정의 산출유량이 감소하기 때문이다. 본 연구에서는 Hantush 공식과 직접 비교가 가능한 단독집수정에 대해서만 계산을 수행하며, 공식은

$$
\begin{aligned}
& \frac{Q}{K T\left(H-h_{0}\right)}= \\
& \left(\frac{t}{L}\right)^{0.1}\left(\frac{D}{L}\right)^{0.15}\left[4.13 m^{0.1415}-1.22\left(\frac{T}{L}\right)\right]\left(\frac{1}{\log _{10} \frac{2 b}{L}}\right)^{A}
\end{aligned}
$$

Table 1. Parameters employed in the Milojevic's formula

\begin{tabular}{cccccccc}
\hline $\mathrm{D}(\mathrm{m})$ & $\mathrm{t}(\mathrm{m})$ & $\mathrm{L}(\mathrm{m})$ & $\mathrm{M}$ & $\mathrm{b}(\mathrm{m})$ & $\mathrm{T}(\mathrm{m})$ & $\mathrm{K}(\mathrm{m} /$ day $)$ & $\mathrm{H}-\mathrm{h}_{0}(\mathrm{~m})$ \\
\hline \hline 0.35 & 6 & 20 & 9 & 100 & 12 & 15 & 14 \\
\hline
\end{tabular}

로 표시된다. 여기서 $\mathrm{A}=0.914+0.0183 \mathrm{~m}-0.348\left(\frac{T}{L}\right)^{\frac{2}{3}}$ 이고, $\mathrm{Q}$ 는 산출유량 $\left(\mathrm{m}^{3} / \mathrm{day}\right), \mathrm{K}$ 는 투수계수(m/day), $\mathrm{T}$ 는 대수층 두께 $(\mathrm{m}), \mathrm{H}$ 는 양수 시작 전에 기반암으로부터 측정한 우물 통 수심 $(\mathrm{m}), \mathrm{h}_{0}$ 는 우물통의 운영수심으로 기반암으로부터 측정한 값 $(\mathrm{m}), \mathrm{t}$ 는 기반암으로부터 수평집수관의 설치높이 $(\mathrm{m}), \mathrm{D}$ 는 여재층을 포함한 수평집수관의 유효직경 $(\mathrm{m}), \mathrm{m}$ 은 수평집수관의 개수, 그리고 $\mathrm{b}$ 는 우물통과 하천수변선 사 이의 거리 $(\mathrm{m})$ 를 나타낸다. Fig. 1로부터 얻은 이들 변수값은 Table 1에 나타내었으며, 계산결과 산출유량으로 $5,972 \mathrm{~m}^{3} /$ day를 얻었다.

\subsection{Hantush공식에 의한 산출유량}

Hantush공식은 점 싱크로 향하는 유선을 적분하여 선형싱 크에서의 유입율을 구한 후 다수의 집수관에 대해 중첩의 원 리를 적용하여 합한 것이며, 그 공식은

$$
\begin{aligned}
& \mathrm{s}_{c}=\left(\frac{Q}{2 \pi K b N}\right)\left\{\ln \frac{\gamma^{\gamma}}{\mu^{\mu}}-(N-1) \ln \frac{\mu^{\mu} j^{j}}{\gamma^{\gamma} \rho^{\rho}}+\right. \\
& 0.5\left[\frac{b}{2 l} \ln \left(\left(\frac{b}{\pi r_{w}}\right)^{2} / 2\left(1-\cos \frac{\pi\left(2 z_{i}+r_{w}\right)}{b}\right)\right)+\right. \\
& \left.\left.\frac{4 b(N-1)}{\pi l} \sum_{n=1}^{M^{\prime}} \frac{1}{n}\left[\frac{\pi}{2}-L\left(\frac{n \pi r_{c}}{b}, 0\right)\right] \cos \frac{n \pi z_{i}}{b} \cos \frac{n \pi\left(z_{i}+r_{w}\right)}{b}\right]\right\}
\end{aligned}
$$

로 표시되고 부호는 Hantush ${ }^{2)}$ 가 사용한 표시를 따랐다. 여기 서 $\mathrm{s}_{c}$ 는 우물통에서의 수위저하 $(\mathrm{m}), \mathrm{Q}$ 는 산출유량 $\left(\mathrm{m}^{3} / \mathrm{day}\right)$, $\mathrm{K}$ 는 투수계수(m/day), $\mathrm{b}$ 는 대수층 두께 $(\mathrm{m})$ 이고, $\mathrm{N}$ 은 수평 집수관의 개수를 나타내며 우물통을 중심하여 균등각으로 배치되어야 한다. 그리고 $\gamma=2\left(a-r_{\mathrm{c}}\right) / l, \mu=\left(2 a-2 r_{\mathrm{c}}-l\right) / l$, $j=l^{\prime} / l, \rho=r_{\mathrm{c}} / l$ 이고, $\mathrm{z}_{i}$ 는 대수층 상단에서 측정한 수평집 
Table 2. Parameters employed in the Hantush's formula

\begin{tabular}{ccccccccc}
\hline$a(m)$ & $r_{c}(m)$ & $I(m)$ & $b(m)$ & $z_{i}(m)$ & $r_{w}(m)$ & $K(m /$ day $)$ & $N$ & $s_{c}(m)$ \\
\hline \hline 100 & 2.5 & 20 & 12 & 6 & 0.175 & 15 & 9 & 14 \\
\hline
\end{tabular}

Table 3. Calculation of $L$ function and summation term

\begin{tabular}{cccc}
\hline $\mathrm{n}$ & $\mathrm{u}$ & L function value & term value \\
\hline \hline 1 & 0.65417 & 1.05841 & $-1.8 \mathrm{E}-05$ \\
2 & 1.30833 & 1.34044 & 0.11431 \\
3 & 1.96250 & 1.55992 & $-1.1 \mathrm{E}-06$ \\
& & summation & 0.11430 \\
\hline
\end{tabular}

수관의 매설깊이 $(\mathrm{m})$ 를 나타내고 이는 대수층의 중간높이에 설치하는 것으로 하였다. $r_{w}$ 는 수평집수관의 유효반경 $(\mathrm{m})$ 을 나타낸다. 또한, 이들 변수에서 $\mathrm{a}$ 는 하천의 수변선에서 우 물통 중심까지의 거리 $(\mathrm{m}), r_{c}$ 는 우물통의 반경 $(\mathrm{m}), l$ 은 수평 집수관의 길이 $(\mathrm{m}), l^{\prime}=r_{c}+l$ 를 나타낸다. 식 (2)에 포함된 $L\left(\frac{n \pi r_{c}}{b}, 0\right)$ 는

$L(u, 0)=\int_{0}^{u} K o(y) d y$

로 정의되는 함수에서 얻을 수 있고, 여기서 $K_{0}(\mathrm{y})$ 는 ' 0 차 제 2종 변형 Bessel함수(zero-order modified Bessel function of second kind)'로 적분을 직접 수행하기도 하지만 보통은 표 로 제공된다.

식 (2)와 (3)에 Milojevic공식에서 적용한 Table 1의 값들 을 적용하여 산출유량의 예측치를 구할 수 있다. Milojevic 공식에 적용하였던 Table 1 의 값을 Hantush식의 표기대로 바꾸면 Table 2가 된다.

식 (2)를 이용하기 위해서는 $L\left(\frac{n \pi r_{c}}{b}, 0\right)$ 를 구해야 하고, 이를 위해서는 먼저 정수 $M^{\prime}$ 의 값을 구해야 한다. 이 값은 $M^{\prime}$ (integer) $>\frac{b}{2 r_{c}}$ 으로 정의되며, $\frac{\mathrm{b}}{2 r_{c}}=\frac{12}{2 \times 2.5}=2.4$ 이므로 따 라서 $M^{\prime}=3$ 이다. 즉 $n$ 이 1 부터 3 까지의 $\frac{n \pi r_{c}}{b}$ 를 구하여 각 값 에 해당하는 $L\left(\frac{n \pi r_{c}}{b}, 0\right)$ 와 $n$ 을 대입하여 summation 항의 값 을 얻는다. 각 $\frac{n \pi r_{c}}{b}$ 에 대응하는 $L\left(\frac{n \pi r_{c}}{b}, 0\right)$ 값과 각 항의 값 및 총합은 Table 3에 나타내었다. 이 summation 항의 값을 식 (2)에 대입하여 산출유량을 얻으면 $5,286 \mathrm{~m}^{3} / \mathrm{day}$ 이 된다.

\section{3. 수치해법에 의한 산출유량}

수치해법을 이용하여 강변여과용 집수정의 산출유량을 계 산하는 방법은 지층의 다양한 구조나 하상폐색 그리고 집수 관의 배치형태 등 현장의 조건을 실제와 유사하게 고려할 수 있어서 세계적으로도 널리 사용되고 있다. ${ }^{7)}$ 다만, 다공 매질인 대수층은 Darcy의 법칙이 적용되지만 여기에 설치 되는 수평집수관은 일종의 관수로이므로 서로 다른 이들 두 흐름영역을 하나의 체계 내에서 해석해야 하는 문제가 발
생한다. 다공질인 대수층에서 강변여과용 집수관을 해석하 는 방법은 정 등 ${ }^{10)}$ 에 정리되어 있으며, 본 연구에서는 수평 집수관을 일정수두 경계조건으로 보는 방안을 채택하였다.

집수정의 산출유량을 수치해로 계산하기 위해서는 먼저 영역을 설정해야 한다. 영역의 전체크기는 $1 \mathrm{~km} \times 1 \mathrm{~km}$ 로 하 였고, 이중에서 하천은 $1,000 \mathrm{~m} \times 400 \mathrm{~m}$ 로 하였으며, 우물통 은 하천의 흐름방향으로 영역의 중간에 설치하였다. 하천에 는 일정수두 경계조건을 적용하였고, 지표를 제외한 나머지 경계는 no-flow경계조건을 적용하였다. Hantush나 Milojevic 공식에서 강우에 의한 지하수 함양을 고려할 수 없으므로 수 치해에서도 이를 고려하지 않았다. 사용된 수치해석 코드는 USGS에서 제작한 MODFLOW ${ }^{11)}$ 를 HydroGeologic사에서 개량한 MODFLOW-SURFACT였으며, 각 블록의 크기는 가 로 $\times$ 세로가 $5 \mathrm{~m} \times 5 \mathrm{~m}$ 이고 높이는 $1 \mathrm{~m}$ 를 적용하였다.

수치모델에 Table 1의 값들을 적용하여 운영하였다. 수평 집수관은 일정수두 경계조건을 적용하되 우물통에서의 수 위와 같게 두었고, 이로 인한 오차는 정 등미의 연구를 이용 하여 계산할 수 있었으며, $1 \mathrm{~cm}$ 보다도 작아 이를 무시하였 다. 불투수층과 상부 모래층의 투수계수는 각각 $1.0 \times 10^{-6}$ $\mathrm{cm} / \mathrm{sec}$ 와 $0.017 \mathrm{~cm} / \mathrm{sec}$ 로 가정하였다. 수치해석에서 연립방 정식을 푸는 방법은 SOR (Successive Over Relaxation)을 채 택하였으며, 계산결과 산출유량은 $6,600 \mathrm{~m}^{3} / \mathrm{day}$ 였다.

\section{4. 결 론}

가상의 동일한 대수층에 강변여과용 집수정을 건설하여 얻게 되는 산출유량을 Milojevic공식, Hantush공식, 그리고 수치해법으로 계산한 결과, 각각 $5,972 \mathrm{~m}^{3} / \mathrm{day}, 5,286 \mathrm{~m}^{3} / \mathrm{day}$, 그리고 $6,600 \mathrm{~m}^{3} / \mathrm{day}$ 이었다. 이들 중 Milojevic이나 Hantush 공식들은 그 유도과정에서 균질한 대수층 등의 여러 가정 이 도입되므로 공식 적용 시 해당되는 전제조건들이 만족 되어야 한다. 또한, 이들 두 공식은 실제의 강변여과에서 일 어나는 하상의 폐색이나 자연지하수의 유입 등을 직접 고 려할 수 없어 그 적용에 주의가 필요하다. 따라서 현장의 다 양한 여건을 비교적 쉽게 고려할 수 있는 수치해법을 적용 하되, 산출유량을 크게 감소시키는 하상폐색을 포함시키는 것이 강변여과의 설계에 가장 적합한 방법이라 할 수 있을 것이다.

\section{KSEE}

\section{References}

1. Ray, C., Schubert, J., Linsky, R. B. and Melin, G., "Introduction," in Riverbank filtration-Improving source-water quality, Ray, C., Melin, G. and Linsky, R. B. (Eds.), Kluwer Academic Publishers(2002).

2. Hantush, M. S., "Hydraulics of wells" in "Advances in Hy- 
droscience" Ven Te Chow (Ed.), Academic Press, Inc.(1964).

3. Zhan, H., Wang, L. V. and Park, E., "On the horizontal-well pumping tests in anisotropic confined aquifers," J. Hydrol., 252, 37 50(2001).

4. Park, E. and Zhan, H., "Hydraulics of horizontal wells in fractured shallow aquifer system," J. Hydrol., 281, 147 158 (2003).

5. Zhan, H. and Park, E., "Horizontal well hydraulics in leaky aquifers," J. Hydrol., 281, 129 146(2003).

6. Milojevic, M., "Radial collector wells adjacent to the river bank," J. Hydraulics Division, Proc. Am. Soc. Civil Eng., 89 (6), 133 151(1963).

7. Grischek, T., Schoenheinz, D. and Ray, C., "Chap. 14. Siting and Design Issues for Riverbank Filtration Schemes," in Riverbank filtration-Improving source-water quality, Ray, C., Melin, G. and Linsky, R. B. (Eds.), Kluwer Academic Publishers(2002).
8. Hoffmann, A. and Gunkel, G., "Bank filtration in the sandy littoral zone of Lake Tegel (Berlin): Structure and dynamics of the biological active filter zone and clogging processes," Limnologica, 41(1), 10 19(2010).

9. Schubert, J., "Chap. 3. German experience with riverbank filtration systems," In Riverbank filtration-Improving sourcewater quality, Ray, C., Melin, G. and Linsky, R. B. (Eds.), Kluwer Academic Publishers(2002).

10. Jeong, J.-M., Park, J.-Y., Lee, J.-J., Kim, Y.-W., Kim, S.-H., "A Study on the Distribution of Hydraulic Head Along the Lateral in a Pilot-Scale Riverbank Filtration," J. Korean Soc. Environ. Eng., 35(5), 334 339(2013).

11. Harbaugh, A. W. and McDonald, M. G., "User's documentation for MODFLOW-96. An update to the U.S. Geological Survey Modular Finite-Difference Ground-Water Flow Model," Open File Report 96 485, U.S. Geological Survey, Reston, Virginia, U.S.A.(1996). 